\title{
UNINTENDED CONSEQUENCES OF MODERNIZATION THEORY ON UNIVERSITY STUDENTS AND GRADUATES IN ZAMBIA
}

\author{
Fumbani MPHANDE ${ }^{1}$ \\ Isaac KABELENGA2 \\ DOI: $10.35782 / J C P P .2020 .1 .04$
}

\begin{abstract}
This ethnographic study explores the unintended consequences of the modernization theory on university students and graduates in Zambia. The study involved 40 participants from the University of Zambia, observed over periods of 9 to 14 years. The study has established that modernization theory has got further-reaching consequences on the participants and the whole Zambian society than what has been documented in the available literature. Whilst some of the consequences are not detrimental to the participants, most of the consequences seem to have negative effects on the Zambian society both in the short term and in the future. Policy implications on how to reverse the negative consequences of modernization theory on university students and graduates in Zambia have also be informed by the findings of the study.
\end{abstract}

Keywords: unintended consequences; modernization theory; tertiary education; Zambia; ethnography

\section{Introduction}

In almost every community in the world, the term modernization is used on a daily basis and has become part of human life. Hall and Midgley (2004) argued that, in this era, each country has either embraced modernization or is undergoing a process of attaining modernization or post-modernization. Modernization cannot remain without the exchange of ideas and thoughts and its consequences. Suffice to note that there is no universally agreed definition upon modernization. This is because the term is relatively used to denote the changes taking place in every sphere of human life

1 Lecturer and Head of Department for the Faculty of Education, University of Africa; e-mail: fmphande@gmail.com

$2 \mathrm{PhD}$ Lecturer at the School of Humanities and Social Sciences, University of Zambia; e-mail: isaackabelenga@gmail.com 
(Kabelenga, 2015; 2018). Hall and Midgley (2004) defined modernization as a process of change with respect to the development in social, economic and political systems. Yasin (2007) thinks that modernization can mean the change from an old attitude to a new one. The Indian Ministry of Human Resource Development (MHRD, 2014) says that modernization can mean coming from the old kind of the society to a completely new society per se. In the thinking of some traditional leaders that participated in Kabelenga's (2018) study on elder abuse in Zambia, modernization is constructed as the tendency among Zambian people to discard the Zambian local values, beliefs, practices, and structures that are regarded as ancient in preference for foreign values, beliefs, practices and structures that are considered to be in tandem with the global society.

Baran (1957) argued that there are various strands in modernization theory which should be embraced by less developed societies if they are to take-off: cultural modernization, economic modernization, technological modernization, and political modernizations among others. The main premise in cultural modernization is that traditional societies are not able to take off because of the backward culture that characterizes them. For instance, it is argued that traditional societies are characterized by cultures of jealousy and dependency, by large family membership and by a lack of financial education manifested through non-savings. These cultures are seen to be detrimental to development. Thus, it is argued that such traditional societies should do away with cultures that impede their take off. Rostow (1971) suggested that all the countries go through the stages of traditional, economic and technological maturity. In a traditional stage, little social change takes place and people do not think much about changing their current circumstances. Change is slow because people hold fatalistic value systems, do not subscribe to the work ethic and save few money. Economic development is accompanied by a growing belief in individualism, competition and achievement. During this stage, people start looking toward the future to save and invest money and discard traditional values. Rostow's (1971) view on the modernization theory embraced capitalism as essential for the transformation from traditional and simple societies to modern and complex ones. With the help of financial assistance and the advancement of high-income countries, low-income countries will eventually enter in the third stage of economic development, namely technological maturity, in which countries improve their technologies, raising their abilities to design, invent and discover new things. Rostow (1971) has been criticized on the basis of discarding traditional values. That is, not all traditional values are bad unless those values that hinder societal progress (Kaya, 2014).

\section{Debates on the role of tertiary education in modernizing human society}

Modernization and education are inseparable concepts. Writers such as Rostow (1971), Bowman and Anderson (1973), Hall and Midgley (2004), or Olaniyan and Okemakinde (2008) support the symbiotic relationships between modernization and education, and argue that modernization brings about innovations, discoveries and new technology in education. In the same vein, tertiary education is seen as a catalyst that propagates scientific skills, knowledge and attitudes that bring about modernization. Thus, the 
authors also think that tertiary education is simply one form of modernization. Modernization theory holds the view that the better developed nations of the world were the first to modernize because they adopted smarter technologies, progressive culture and attitudes by appropriately educating the majority of their citizens. Thus, if traditional societies (less developed countries) are to develop, they should do what developed nations did (Rostow, 1971; Bowman and Anderson, 1973). In supporting this debate, Todaro (1982) added that the key factor in the modernization of developed nations was education. Through education, children would become modern and acquire, among other things, new perceptions of time and reward, as well as a strong sense of themselves as individuals.

\section{Modernization of Third World Countries}

In the third world countries, modernization theory was popularized in the 1950's and 1960's to explain the relative underdevelopment of Latin America, Africa and Asia (Todaro, 1982). Modernization theory assumed that development was a not a linear process, consisting of a sequence of stages through which a country must pass. Thus, as modern attitudes, values, skills and technologies spread from the industrial to the 'traditional' nations, first to their cities and then to the hinterlands, these nations would become modern. Alongside education, another of the primary agents of the diffusion process was thought to be a progressive nationalistic bourgeoisie. Modernization theorists argued that this progressive bourgeoisie would lead the course of national development in the national interest and facilitate the spread of modernization (Carmody, 2004). The key to modernization theory was its use of the nation state as a unit of analysis: underdeveloped nations were thought to be able to pursue a path of autonomous development. The major reason for the lack of development was that people did not have sufficient education to support a modern occupational structure (Hall and Midgley, 2004; Hackett, 2004).

\section{Modernization theory and tertiary education in Zambia}

In Zambia, modernization theory was popularized in the 1960's to explain the relative underdevelopment of the country (Turok, 1979; Kelly, 1999). The focus in the modernization theory was its use of the nation state as a unit of analysis. One of the major reasons for the lack of development in Zambia was that people did not have sufficient education to support a modern occupational structure. According to the theory, education had two key functions: first, it should respond to the national needs for trained manpower and, second, it should socialize a nation's population into modern values, attitudes, skills, and technologies. In response to such perceived benefits, Zvogbo (1999) and Carmody (2004) suggested that the education agenda in Zambia should focus on improving the literacy rate and on human resource development. Planners were anxious to develop policies and programs which would make this possible. Strategies included the rapid expansion of primary and secondary education with a view towards the development of human resources, developing training programs to equip the youth with the necessary skills for employment in industry, commerce and entrepreneurship. Further on, the University of Zambia was 
established in 1965 to develop qualified manpower capable of dealing with the ongoing sophistication of industrial technology. The objectives of these strategies were to ensure that the economy continued to operate at optimum level, and to ensure a definite improvement in the quality of the lives of Zambian people.

Since the early 1960's, Zambia has embarked on the modernization of society through promoting tertiary education. This is evidenced in that, by 2018, Zambia had over 60 universities (Zambia's Higher Education Authority, 2018). Interesting is that a search into the programs of the University of Zambia and of other universities in the country indicates that modernization theory is taught across all disciplines. For example, in the School of Medicine, the primary focus is on conventional medicine in addressing health problems at the expense of Zambian herbs. In the School of Engineering, the emphasis is on the use of advanced western technology in the development of Zambia's industries. In the School of Humanities and Social Sciences, the emphasis is on embracing progressive culture across every sphere of the Zambian society. Although no actual national statistics are available on the number of Zambians with tertiary education, an increase in the number of universities and the teaching of modernization theory in universities means that modernization theory is part of the lives of students and graduates.

\section{Previous empirical studies on modernization in Zambia}

Studies undertaken so far have established that modernization has brought about change in different areas of the Zambian society. Although no actual national statistics are available, notable changes include the import of western primary, secondary and tertiary educational curricula, of foreign technology across different sectors of the Zambian society, the increase in the number of Zambian graduates opting for specialized training in developed countries, the increase in the number of Zambians that are pursuing tertiary education, the change of career pathways, and the use of information communication and technology (ICT) as evidenced in the number of Zambians using e-learning, e-banking, e-library and social media (Kelly, 1991).

Other studies have established that education systems in Zambia are heavily controlled by the core societies. For instance, the core societies have a high influence even in designing and implementing the national school curricula, since experts from developed countries are heavily involved during this process. In this regard, the Zambian curricula are mostly designed by core societies (Kelly, 1991; Lungwangwa, 2001; Henriot, 2002). Kabelenga (2018) has also established that modernization has contributed to the breakdown of the extended family system, which has been replaced by the nuclear family. Kabelenga also established that modernization has contributed to the weakening of the villages as a social unit for informal protection among the aged and other vulnerable people in the countryside. Many Zambians have abandoned their villages and migrated to the centers that they considered to have progressive cultures and which offered opportunities for prosperity among other benefits of modern societies as postulated by the modernization theory.

One of the gaps that is evident is that the huge volume of scientific knowledge is biased towards intended consequences of the modernization theory on the societies where it is 
implemented. This is because almost all the consequences previously mentioned are the primary objectives of different strands of the modernization theory (Hall and Midgley, 2004; Hackett, 2004; Yasin, 2007). However, this approach to evaluating the outcomes of modernization theory has left out the unintended consequences. From a sociological point of view, every planned intervention has got intended and unintended consequences. To have broader and deeper perspectives into any planned interventions, there is a need to understand both the intended and unintended consequences. Considering unintended consequences is one way of broadening scientific knowledge, as new insights are generated when scientists go beyond the primary objectives of the intervention documented on paper (Giddens, 2010).

The term unintended consequences describes unforeseen or unanticipated consequences, while intended consequences are desirable outcomes that are done on purpose. Thus, the main aim of this study was to establish the unintended consequences of modernization theory on students at and graduates of the University of Zambia. The ultimate goal of the study was to broaden the scientific knowledge by bringing in the existing scientific knowledge the unintended consequences of modernization theory and, specifically, on students and graduates at the University of Zambia. Thus, it is the hope of the authors that this paper will spark intense debates in the scientific community about the consequences of modernization theory in modernizing Zambia. It is also hoped that this paper will have enough academic power to change ways of thinking about the symbiotic relationships between modernization theory and tertiary education among the change agents at all levels of the Zambian society and beyond.

\section{Study Methodology}

An ethnographic study was used for this research. In particular, one-to-one in-depth interviews and direct participant observations with 40 undergraduate students pursuing various degree programs at the University of Zambia were undertaken. Creswell (2003) advised that ethnography is a qualitative design in which the researcher describes and interprets the shared and learned patterns of values, behaviors, beliefs, and language of a culture-sharing group for a prolonged period of time, most often through participant observation, in which the researcher is immersed in the day-to-day lives of the people and observes and interviews the group participants. Van (2013) advised that ethnography is a method involving observing, talking, studying artifacts and some degree of participation from the participants. Thus, in order to understand the changes brought about by the modernization theory on students during and after completing their studies at the University of Zambia, the participants were studied not only during their years as students, but also over a period of five years after graduation. The students were those who had come straight from secondary schools and had not received any tertiary education from any other learning institutions. We assumed that those categories of students had not yet been introduced to the modernization theory and, thus, were less influenced by the tenets of this theory. Because of that, we further assumed that such categories of students were still much embedded into local Zambian cultures, beliefs and practices. As such, we further assumed that, after these categories of students have been grounded into modernization theory, we would be able to assess 
them as to whether they would still hold to their local cultures, beliefs, traditions and practices. Thus, in their first days of arrival at the University of Zambia, we established friendships with them by close interaction, giving them different forms of assistance such as orientation, helping them on how to write assignments, where to find relevant books, eating with them and visiting them more often. In the process of interaction, we asked them a number of questions relating to their local culture, beliefs and practices in relation to food preferences, possibilities of marrying their own tribesmen/women and language preferences for their anticipated children. We then recorded their responses in our research diary. Most of them expressed preference for their own culture in all their areas of life, saying that their cultures were better than foreign cultures. Only those who expressed preference for their local cultures were targeted for this study.

The participants were drawn from different schools (faculties) at the University, such as the School of Natural Sciences, the School of Medicine, the School of Education, and the School of Humanities and Social Sciences. 40 participants (20 males and 20 females) were studied for a period between 9 and 14 years (between 2004 and 2018). During 2004 and 2008, the researchers were students at the University of Zambia and from 2009 to 2018 they were lecturers. Thus, they closely interacted with the participants, who became like personal friends and opened up in dialogue, which helped collect even sensitive information. At the beginning of the study, participants were aged between 21 and 23, while at the end between 29 and 35 years. They also came from different ethnic groupings. Zambia has seven major ethnic groupings (Lozi, Lunda, Luvale, Kaonde, Bemba, Tonga and Nyanja), each with its own cultures (Zambia Central Statistics Office, 2000). In order to collect rich data in terms of local Zambian culture, the participants were drawn from all seven major ethnic groupings.

Verbal expressions were analyzed using content analysis. The expressions of the participants and the meanings which they attached to the expressions were analyzed. Observations in terms of lifestyles were analyzed by using observational analysis. The researchers analyzed behavior, language use and the food that the participants ate. After all data was gathered, the next step consisted of a search for patterned regularities in the data. The participants were then evaluated in terms of standards that they set for themselves during their studies and after graduating from the University of Zambia. Finally, we drew connections between the culture-sharing groups in comparison with the tenets of modernization theory (Wolcott, 1994; Creswell, 2003). From the analysis, we noticed the following changes in the majority (35) of the participants:

a. preference for inter-tribal marriages;

b. weakening of the use of the local languages and increase in multilingualism;

c. preference of English as the main language of communication among their children;

d. abandonment of certain traditional practices.

Erlingsson, Saveman and Berg (2005) advised that the foundation for credibility also lies within offering examples of statements from the original texts in the findings section, hence, for this study, representative statements from the interviews have been 
used to show each of the changes that were established. After reflecting upon the collected data, we further deduced that it revolved around two scientific concepts, namely power and relationship. Thus, we selected these concepts to serve as analytical tools when interpreting the data. In this study, the concepts of power and relationship are used to mean the following: Power is the ability of the knowledge acquired to influence the behavior of the recipient or another person or institution to do something which they would not have done if they were just by themselves (Weber 1957; Foucault, 1980; Mahajan, 2004); Relationship is used to denote a wide array of interpersonal interactions between the recipient of knowledge and other members of society (Osei-Hwedie, Mwansa and Mufune, 1990). The established changes and the concepts of power and relationship form the major changes presented and discussed in the findings section. For ethical considerations, the real names of the participants have been replaced with the aliases such as F1 for female participant 1, F2 for female participant 2, M1 for male participant 1 and so forth.

\section{Findings and Discussions}

Out of the findings of this study, we established the following to be the major unintended consequences of modernization theory on the university students and graduates who we studied:

\section{a. Preference for inter-tribal marriages}

It was evident that, when both male and female students were freshmen at the university, most of them had held a belief that it was better for them to marry from their own ethnic grouping. A number of the interviewed participants actually reported that they were already in intimate relationships with someone from their own ethnic grouping. For example, when F1 was in her first year at university, she mentioned:

"I cannot marry [someone] from a different tribe. Marrying someone from your own tribe is also always better because you share the same culture. As a result, it is easier to have stable marriage. This is because you have a number of things in common. And traditional culture is very important in marriage"

In her third year of study, we asked her whether she was still considering marrying from her own ethnic grouping. Her reply was:

"With the academic knowledge that I have acquired from this university, my mind has been opened. Those traditional beliefs that I had have been broken. They were backward. I think the right thing is to marry a person who is progressive, regardless of the ethnic grouping that one comes from."

These responses were common for all participants. The interpretation that arises from the data is that knowledge advanced by modernization theory has academic power to weaken traditional knowledge. This is because it can make the recipients of such knowledge to change the way they think about human life and, ultimately, the way they relate with their society, as modernization theory uses a comparative evidence-based approach to life. Thus, because learners are provided with different perspectives on the dynamics of human progress, they are convinced to adopt options that are widely 
adopted by people in progressive societies (Turock, 1981; Midgley, 1995; Hall and Midgley, 2004).

\section{b. Weakened use of local languages and increased multilingualism}

Another change that we observed in all the participants was a weakening of the use of local languages in the detriment of multilingualism. We observed that when the participants were freshmen, most of them used their local languages. Even before the end of their first academic year, almost everyone learnt popular local languages such as Bemba and Nyanja. As the students learned third and fourth languages, they seemed to believe that one sign of civilization (modernity) was the use of popular languages. Thus, it was common throughout this study to see and hear students use discriminating languages against fellow students who often used their local languages. Interesting was that some participants who supported the use of popular local languages were themselves not native speakers of popular languages. They were also senior students who had studied in the university for three years and more. Below were some representative remarks of the participants:

"(S)he is very backward. (S)he is inclined to using their local language. $S($ he) is not even ashamed of herself/himself. (S)he is engulfed in traditionalism. You need to be multilingual in this modern society for you to survive or work well.” (F17)

"Stop using that local language. People consider you to be backward. Strive hard to use Bemba and Nyanja. In that way you will easily get accepted by your colleagues". (M7).

The above data can be interpreted using the concepts of language power and interstudent relationships (Foucault, 1980). In cultural modernization, it is theorized that there is power in language used. Depending on the language used in a particular society, developmental interactions can be easier or difficult. It is theorized that easier interactions can bring about development in society, and limited interactions can put constraints on development. This is why popular languages are encouraged in modernization theory (Foucault, 1980; Rodney, 1973; Kabelenga, 2017). This interpretation is evident in the above remarks, in that the participants hold the view that, by not using certain local languages, interactions among all the university students would be easier and ultimately lead to the development of individual students and the whole Zambian society. However, from the data it was vivid that the type of power and relationships are weakening the local languages of some students. That was evident in that due to humiliating inter-student relationships, the higher the students advanced in their studies, the more they reduced on using their local languages in preference for popular local languages. This has the power to make unpopular local languages not to be learnt by students of different ethnic groupings and/or nationalities. In turn, this has power to hinder inter-cultural transmission which is also good for individual and societal development (Giddens, 2010; Kaya, 2014).

\section{c. Preference of English as the main language of communication among graduates' children}

It is also evident from the data that modernization theory has resulted into prompting university graduates to influence their children resort to using English as the main 
language of communication as opposed to the use of the parents' mother tongues. In our study, it is common to find graduates' children not able to speak the mother tongues of their parents. Three reasons explain this inability. First, most graduates think that the use of English language is an indication that the whole family is modern. Second, graduates think that if their children speak English from a tender age, they would find it easier to interact with the teachers and fellow pupils at primary and secondary levels and, which would result in better performances at school. Third, due to inter-tribal marriages, it is difficult for both parents to speak to each other well in their local languages. As a result, the use of English is preferred for the children. Consequently, parents have not provided the platform that can make the children speak the local languages of the parents. When asked why their children could not speak their parents' local languages, one male participant who had graduated nine years ago commented:

"It is very difficult for our children to speak our local languages. This is because my wife and I are not coming from the same tribe. I cannot speak well [in] my wife's mother tongue. Neither can she speak. well in my mother tongue. So we have to use English so that it is easier for us to communicate. We also think this will help our children to communicate well when they are in school. This is because English is the major medium of instruction in the private schools where we send our children." (M11).

A similar explanation has been given by a female graduate in a separate interview:

"With these inter-tribal marriages in which we are, it is very difficult to teach children our mother tongues. The wife has a different mother tongue and the husband has his own mother tongue. So it is difficult. But even if they are able to speak in local languages, where does it take them? Because at school, the main language used is English. So it is better to use English even at home. That makes them to do well at school. This is because they are able to communicate well with the teachers." (F5).

These interview answers can be interpreted using the concepts of mental power, intermarriage relationships and societal relationships. It is evident from the answers that modernization theory has played a role in mentally changing the way graduates think about the way their children should relate with the parents and other societal members. This interpretation is based on the ground that from the voices of the participants, consideration for the positive effects on their children when they understand and use English is at the centre stage for their preference of their children learning English. This is in line with the language modernization theory which theorizes that language plays a role in individuals' and societal progress. For example, it is theorized that with easier communication, interaction and exchange of knowledge and skills among societal members can be easier and in turn bring about development (Rodney, 1980; Mangal, 1995; Yasin, 2007).

\section{d. Abandonment of certain traditional beliefs and practices}

It is also evident from the answers that the abandonment of certain traditional beliefs and practices is common among university students and graduates. This is because through modernization theory, students and graduates are brought to think that certain traditional beliefs and practices are inimical to their progress as well as to the progress 
of the whole society (Todaro, 1982; Hall and Midgley, 2004). As a result, traditional practices which cannot be subjected to empirical testing are sidelined. Instead, the study has established that modernization theory has made students and graduates support and adopt practices which are subjected to empirical evidence. For instance, in 2004, a first year male student who entered the School of Natural Sciences with the intention to study human medicine had this to say about the use of herbs:

"Herbs are okay. This is because certain health problems can be well cured using herbs. So we cannot run away from [the] use of herbs even if they cannot be subjected to laboratory testing." (M9).

In November 2018, one of the researchers visited the same participant (M9) at his office. The participant had graduated from the medical school and worked as a medical doctor at one public hospital in Zambia. The following dialogue took place:

Researcher: I have come to consult you my brother over one problem that I have. My nephew has a problem of fitting. We have tried conventional medicine with no positive effects at all. I would like to ask you what you think about the use of herbs. As a medical doctor, do you have specific herbs which you can recommend to us as a family?

Participant: I cannot encourage you to think about the use of herbs. No! Herbs? No, they are dangerous.

Researcher: But, currently, there is a scientific debate among social scientists on what is called 'local ways of knowing and doing.' The bottom idea in the debate is to encourage people especially from developing countries to use their traditional approaches and practices in addressing their local problems even if those approaches and practices are not tested using western science.

Participant: I cannot advise you to use traditional medicines. This is because they are not subjected to any scientific testing. You are just told by the berbalist to cut that root of the tree, and then put them one by one in the pot and pour water on the roots, then start drinking the saturated water. So how are you going to know the concentration of the herbs? How are you going to know the content?

Researcher: To me, what is important is the problem being solved. So it does not matter whether it is traditional medicine or western medicine. What is important is the problem to be solved. That is the way our ancestors lived. They depended on herbs and lived healthy lives and even longer than us who are using conventional medicine.

Participant: That is up to you. But as a medical doctor, I don't believe in the use of traditional medicine and cannot encourage you to use it...

This dialogue suggests that modernization theory is influencing the way students and graduates relate with the Zambian traditions and practices. It is evident from the episode that Zambian traditions and practices are being sidelined by some students and graduates because of the influence of modernization theory. For example, in modernization theory, the use of traditional practices that cannot be subjected to empirical testing is not supported at all. Rather, only practices that can be subjected to empirical testing and proved to address societal problems are supported (Fook, 2002; Kaya, 2012; Kabelenga, 2015). This perspective is evident in the responses provided by 
the medical doctor participant. From holding the perspective that herbs played a vital role in addressing health problems upon entering university, once graduated, the participant changed his perspective, claiming that traditional herbs cannot be supported. It seems from the data that this change in perspective has come about due to knowledge acquired from modernization theory. This means that modernization theory has got the power to change the way students and graduates relate with their local beliefs, local practices, local communities and the whole society.

\section{Conclusions}

Modernization theory had far reaching consequences on the university students and graduates whom we studied than what was documented in most literature. The unintended consequences that have been established by this study include preference for inter-tribal marriages among the students and graduates; weakening of the use of their local languages and increase in multilingualism; the use of English as the main language of communication among the students' and graduates' children; abandonment of certain traditional beliefs and practices by the students, graduates and their children.

Similar effects have been recorded on both male and female students and graduates that participated in this study. By providing the learners with a progressive world outlook, modernization theory makes both male and female students to change the way they perceive life. Because learners are provided with a more appealing world, the whole Zambian society could develop by abandoning the backward traditional beliefs and practices. This results into changing the overall relationships with the immediate world such as family members, traditional values, beliefs and practices.

Modernization theory produces effects that transcend the primary beneficiaries. For example, the children of students and graduates, as well as the larger society are impacted. The graduates' children do not continue learning certain traditional beliefs and practices on the ground that such beliefs and practices are inimical to the progress of the children and of the whole society. Knowledge acquired from modernization theory by students and graduates is transferred to other levels of Zambian society in a ripple manner and in both obvert and subtle ways. For instance, we observed in the study with medical students that in the process of socialization and trying to find solutions to the health problems faced by societal members, students and graduates derive knowledge from modernization theory. Because of that, knowledge contained in modernization theory ends up being shared with family and other societal members who never sat in a university classroom to listen to the teachings contained in modernization theory. As a result, the knowledge continues to spread to different levels of society.

Modernization theory has power to weaken and wipe away some Zambian traditional beliefs and practices. This conclusion is based on the ground that in this study we established that due to the knowledge that they acquired from modernization theory, all the participants began to discard some of the Zambian traditions and beliefs and practices which they initially believed in and supported. Based on the findings of the present study, we foresee the situation where a number of Zambian traditional beliefs 
and practices will go into extinction. With the increase in the number of universities, Zambians will receive university education of which modernization theory is part of.

The findings of this study should not be generalized to other parts of the world, because they are only based on the results established from 40 participants at the University of Zambia. Notwithstanding that the findings of this ethnographic study are drawn from a field site with unique features and cannot be generalized, we think that the results of the current study have got the power to spark intense debates in the global scientific community about the consequences of modernization theory.

\section{Policy Implications}

Two policy implications can be generated. First, there is an urgent need for the Government of Zambia to find ways of reversing the negative consequences of modernization theory on university students and graduates. One way this can be done is by introducing a lecture such as "Progressive Zambian Culture". The subject should be learnt by pupils and students ranging from primary to tertiary education. In this way, students and graduates would be provided with the platform to acquire knowledge about progressive Zambian culture even if it is not subjected to empirical testing in relation to modernization theory. Second, more empirical evidence is needed to convince university students and graduates that some Zambian traditional beliefs and practices are good for the development of Zambia. Thus, the Government of Zambia and other development partners should support studies that focus on establishing Zambian traditional beliefs and practices that have played vital roles in addressing Zambian problems. In the same vein, similar studies should be undertaken on the problems brought about in the Zambian society due to the teachings of modernization theory. In this way, students and graduates would have balanced knowledge about the pros and cons of modernization theory and Zambian culture.

\section{Aknowledgements}

We would like to thank the 40 participants that participated in this study. The data that we collected from them has formed the basis for writing this article.

\section{References}

Agar, M. (2010). On the ethnographic part of the mix: A multi-genre tale of the field. Organizational Research Methods, 13(2), 286-303.

Bowman, M.J., \& Anderson, C.A. (1973). Human Capital and Economic Modernisation in Historical Perspective, in F.C. Lane (ed.), Proceedings of the Fourth International Conference of Economic History 1968. Paris: Mouton.

Baran, P. (1957). The Political Economy of Growth. New York: Monthly Review Press.

Carmody, B. (2004). The Evolution of Education in Zambia. Lusaka: Book World Publishers.

Creswell, W.J. (2003). Qualitative Inquiry \& Research Design - Choosing among Five Approaches (Second Edition). London: Sage.

Erlingsson, C.L., Saveman, B.I., \& Berg, A.C. (2005). Perceptions of Elder Abuse in Sweden: Voices of Older Persons. Brief Treatment \& Crisis Intervention, 5(2), 213-227. 
Foucault, M. (1980). Power/Knowledge: Selected Interviews and Other Writings 1972-1977. New York: Pantheon Books.

Giddens, A. (2010). Introduction to Sociology. New York: Norton \& Company.

Hackett, R. (2004). Modernising Education Systems. Trinidad: Trinidad Guardian Newspaper.

Hall, A. \& Midgley, J. (2004). Social Policy for Development. London: Sage Publications.

Henriot, P. (2002). “What Ethic should guide Globalization?”. JCTR Bulletin, 51, 7-9.

Kabelenga, I. (2015). The Relevancy of Postmodernism in Understanding Elder Abuse:

Implications on Social Work Education and Practice. Postmodernism Problems, 5(1), 38-55.

Kabelenga, I. (2017). Zambian elders' experiences and perceptions of the generation gap. Anthropological Researches and Studies, (7), 3-15.

Kabelenga, I. (2018). Elder Abuse in Rural and Urban Zambia: Interview study with community leaders. Rovaniemi: Acta Universitatis Lapponiensis 372.

Kaya, O.H. (2014). Revitalizing African Indigenous Ways of Knowing and Knowledge Production. Washington D.C.: E-International Publishing.

Kelly, M.J. (1991). Education in a Declining Economy: The Case of Zambia: 1975-1985. EDI Development Policy Case Series. Analytical Case Studies Number 8. Publications Sales Unit, Washington D.C.: World Bank.

Lungwangwa, G. (1988). The rationale for basic education in developing countries: A critique of the ideology of reform in education. Critical Arts. South-North Cultural and Media Studies, 5(1), 11-22.

Mahajan, V.D. (2004). Political Theory. New Delhi: Sterling Publishers.

Mangal, S.K. (1995). Introduction to Psychology. New Delhi: Sterling Publishers Private Limited.

Midgley, J. (1995). Social Development: The developmental perspective in social welfare. London: Sage.

Government of India, Ministry of Human Resource Development (2014). Educational Statistics at a Glance. New Delhi. Available online at: https://mbrd.gov.in/sites/upload_files/ mbrd/files/statistics-new/EAG2014.pdf

Olaniyan, D.A., \& Okemakinde, T. (2008). Human capital theory: Implications for educational development. Pakistan Journal of Social Sciences, 5(5), 479-483.

Rodney, W. (1973). How Europe Underdeveloped Africa. London: Bogle-L'Ouverture Publications.

Rostow, W.W. (1971). Politics and the Stages of Growth. London: Cambridge University Press.

Todaro, P.M. (1982). Economic Development in Less Developed Countries, 2nd Edition. London/New York: Pearson.

Turok, B. (1979). Development in Zambia: A reader. London: Zed Press.

Weber, M. (1957). The Theory of Social and Economic Organization. Glencoe, Ill.: Free Press.

Wolcott, H.F. (1994). Ethnography: A Way of Seeing. Oxford: Altamira Press.

Yasin, E. (2007). Modernization and society. Report for the VIIIth International Conference 'Modernization of Economy and Public Development', Moscow: Higher School of Economics.

Zvobgo, R.J. (1999). The Post-Colonial State and Educational Reform: Zimbabwe, Zambia, and Botswana. Harare: Zimbabwe Publishing House.

Zambia Central Statistics Office (2010). Census of Population and Housing. Lusaka: Central Statistical Office. Available online at: https:/ / www.zamstats.gov.zm/phocadownload/2010_Census/2010\%20Census\%20of\%20Population $\% 20$ National $\% 20$ Analytical\%20Report.pdf

Zambia's Higher Education Authority (2018). HEA 2018-2021 Strategic Plan. Lusaka: Higher Education Authority. Available online at: bttp:/ / wmw.hea.org.zm/index.php/downloads?download=11:2018-2021-strategic-plan-of-the-highereducation-authority-bea 